\title{
La mitografía como exégesis homérica: estudio de algunos ejemplos del Mythographus Homericus y los escolios menores a Homero*
}

\author{
Joan Pagès \\ Universitat Autònoma de Barcelona \\ joan.pages.cebrian@uab.cat \\ ORCID iD: https://orcid.org/0000-0001-5393-1042
}

\section{Mythography as Homeric Exegesis: Study of some Examples of the Mythographus Homericus and the Scholia Minora to Homer}

La crítica moderna ha tratado el denominado Mythographus Homericus $(\mathrm{MH})$ fundamentalmente como un manual mitográfico. La denominación misma que se ha impuesto es una muestra evidente de ello. En cambio, no se ha estudiado en profundidad como una obra de exégesis homérica. Este artículo propone una aproximación al método exegético del MH a partir del análisis de ejemplos de los papiros y de algunos escolios. El MH comenta el texto homérico desde enfoques diversos, principalmente el mito referenciado, el contexto mítico y la glosa mitográfica a un término concreto. A pesar de la ausencia, en la mayoría de los casos, de marcas formales de comentario, el lector antiguo sin duda leía el texto como tal en virtud de determinadas convenciones de lectura. La tradición del MH, a pesar de haber sido alterada en su redacción a lo largo de su transmisión, se mantiene estable en sus contenidos y método.

Palabras clave: Mythographus Homericus; escolios menores a Homero; mitografía.
Modern criticism has treated the so-called $M y$ thographus Homericus (MH) primarily as a mythographic manual. The very name that has been imposed is an evident example of this. On the contrary, it has not been studied in depth as a work of Homeric exegesis. This article proposes an approach to the exegetical method of the $\mathrm{MH}$ based on some examples from the papyri and scholia. The $\mathrm{MH}$ comments on the Homeric text from different perspectives, mainly the referenced myth, the mythical context and the mythographic gloss to a specific term. In spite of the absence, in most cases, of formal commentary marks, the ancient reader would understand the text as a commentary under specific reading conventions. The MH tradition, despite having been altered in its wording throughout its transmission, remains stable in its contents and its method.

Key words: Mythographus Homericus; Scholia minora to Homer; Mythography.

Cómo citar este artículo / Citation: Pagès, Joan (2021): «La mitografía como exégesis homérica: estudio de algunos ejemplos del Mythographus Homericus y los escolios menores a Homero», Emerita 89 (1), pp. 1-26.

* Proyecto FFI2016-79906-P (AEI/FEDER, UE): «Estudio diacrónico de las instituciones socio-políticas de la Grecia antigua y de sus manifestaciones míticas».

Copyright: (C) 2021 CSIC. Este es un artículo de acceso abierto distribuido bajo los términos de la licencia de uso y distribución Creative Commons Reconocimiento 4.0 Internacional (CC BY 4.0). 


\section{Introducción}

El objetivo de este trabajo es evaluar algunos ejemplos de las llamadas historiae fabulares del texto atribuido al autor hipotético denominado Mythographus Homericus (en adelante $\mathrm{MH})^{1}$ con el propósito de aportar más datos que permitan definir mejor la naturaleza de la obra en sí y el tipo de exégesis homérica realizada por su autor (o autores). Los estudios sobre el MH publicados hasta la fecha se han centrado básicamente en dos aspectos: por una parte, el de la papirología, la transmisión manuscrita, la crítica textual y los problemas ecdóticos que suscita, y por otra, su consideración como manual mitográfico. El hecho de que el MH parezca en una primera lectura una recopilación de resúmenes de mitos (historiae fabulares) ha despertado, desde la tesis de Panzer y, sobre todo, desde la aparición de los primeros papiros, el interés de los estudiosos de la mitografía. Sin embargo, desde la crítica homérica el tema se ha abordado como materia marginal. Es especialmente significativo el hecho de que Erbse eliminara las historiae fabulares de la tradición de los escolios D de su edición de los escolios a la Ilíada. El corpus de historiae fabulares ha sido percibido como una interpolación y tratado como tal hasta los trabajos de Montanari y van Thiel. La edición de los escolios D de van Thiel otorga a las historiae fabulares el lugar que les corresponde, y nos permite analizarlas en su contexto exegético de forma apropiada. Montanari (1995) ya advirtió sobre la importancia del MH como texto exegético, seguido por Pagès $(2005 ; 2007)$. En definitiva, el corpus conocido como MH no ha sido objeto todavía de un estudio sistemático desde el punto de vista de la exégesis homérica².

${ }^{1}$ El nombre de Mythographus Homericus fue forjado por J. Panzer (1892). Para este estudio en concreto hemos tomado en cuenta Montanari 1995a, Cameron 2004 y Pagès 2007. Sobre las historiae fabulares y los escolios menores véase Pfeiffer 1937, quien estableció la relación entre el texto de los papiros y los escolios estudiados por Panzer en su tesis de 1892; Diller 1935; van der Valk 1964; y más recientemente la problemática ha sido retomada a partir de nuevos hallazgos de papiros: Montanari 1988, pp. 341-344; Montanari 1995a, 1995b, pp. 74-77; van Rossum-Steenbeek 1998, cap. 3; Cameron 2004, cap. 3; Dickey 2007, p. 26; Higbie 2007, pp. 250-251; Kenens 2012, pp. 160-164; Delattre 2016; Pagès 2017.

2 Tampoco en el coloquio «Mythographus Homericus: 125 years after Panzer» (Universidade de Lisboa, 16-17 de noviembre de 2017) se abordó a fondo la cuestión del valor exegético del $\mathrm{MH}$. Las contribuciones presentadas se publicarán próximamente en Pagès y Villagra (en preparación). 
La percepción de las historiae como algo ajeno al corpus escoliográfico se origina en el hecho de que la mayoría de ellas pueden ser tratadas como un texto per se. La lectura de los escolios D parece sugerir que estas hayan sido transcritas de un manual. Pero los papiros demuestran que el texto ya estaba estructurado como un comentario desde antiguo, a pesar de que las marcas formales de comentario son muy escasas. La historia se yuxtapone al lemma sin más explicación y, en la mayoría de los casos, el texto de la historia no hace mención alguna del lemma de manera explícita.

A pesar de lo expuesto, debemos tomar en consideración las convenciones del género en virtud de las cuales el lector es consciente de que está leyendo un comentario a un pasaje o a un término concreto del texto homérico. Cada historia responde a uno o varios interrogantes que suscita el texto de Homero, como veremos. Dichos interrogantes no son nunca explícitos, a la manera de los llamados escolios exegéticos ${ }^{3}$, en los que se plantea una cuestión

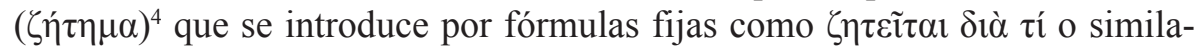
res, a las que se da una respuesta introducida por una fórmula correspondien-

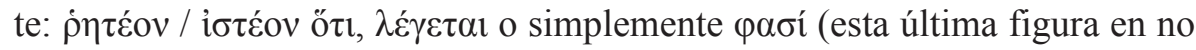
pocas historiae fabulares sin que se haya explicitado la fórmula de interrogación al inicio). Veamos un ejemplo de ello. En un escolio exegético a $\mathrm{Il}$. I 180 conservado en el códice $\mathrm{G}$ leemos ${ }^{5}$ :

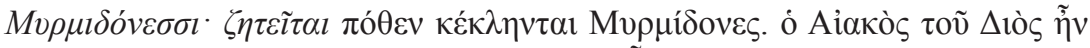

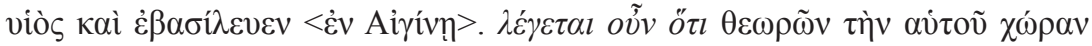

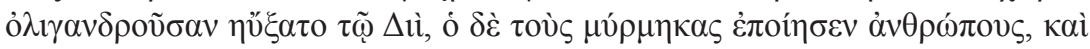

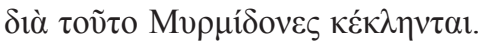

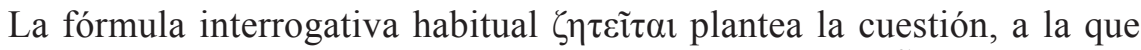
se responde mediante una fórmula en correlación $\lambda \dot{\varepsilon} \gamma \varepsilon \tau \alpha \iota$ oũv ö $\tau$, que a su vez introduce una breve noticia sobre el origen mítico de los mirmidones de Egina.

${ }^{3}$ Erbse 1969, pp. XXII-XXIII.

${ }^{4}$ La Quaestiones Homericae de Porfirio sin duda se fundamentan en esta tradición exegética que debe de haberse originado desde antiguo. Porfirio representa una corriente erudita y filológica dentro de esta tradición. Véase MacPhail 2011.

${ }^{5}$ El códice G (Genevensis 44) fue publicado por Jules Nicole (Nicole 1891). En el segundo volumen de la publicación se recogen los escolios del s. XIV atribuidos a Teodoro Meliteniota, colección a la que pertenece el escolio transcrito y comentado. 
Pues bien, comparemos este escolio con el que aparece en los códices de clase D como comentario al mismo pasaje en forma de historia fabularis ${ }^{6}$ :

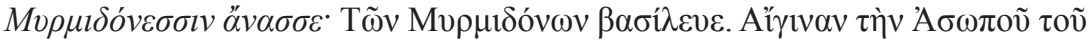

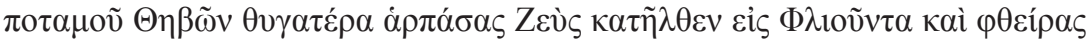

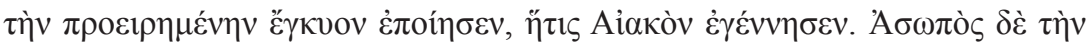

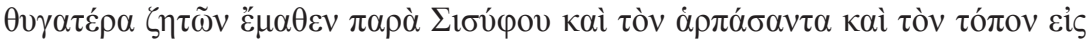

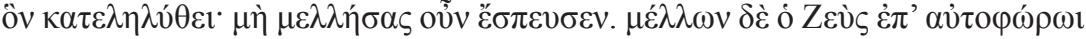

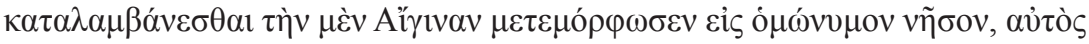

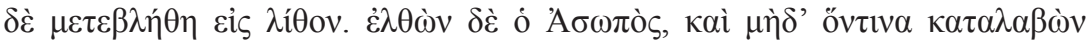

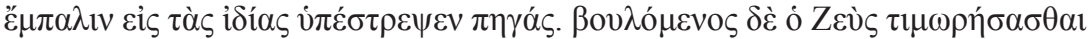

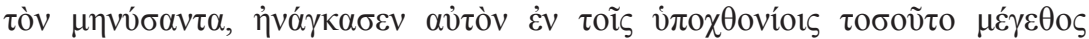

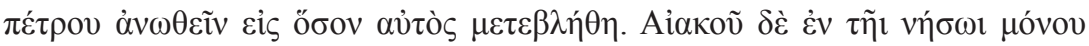

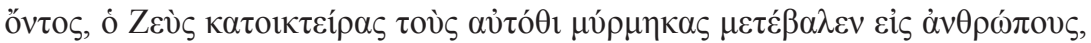

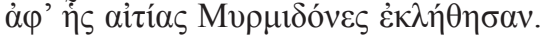

Ambos escolios se refieren a la misma tradición mítica, originada por la

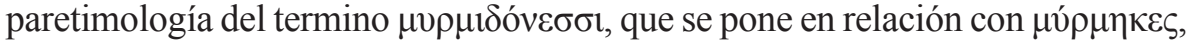
'hormigas'. Pero las diferencias del formato del escolio son evidentes: si bien en el escolio exegético se concibe como una pregunta formular seguida de una respuesta breve y concisa, la historia es un relato completo que se narra de manera directa, sin fórmula introductoria, sin ni siquiera un mínimo nexo. La narración, pues, ofrece detalles que no son relevantes para la interpretación del pasaje homérico, pero permiten una visión del relato en su conjunto.

Parece, pues, que las historiae fabulares evitan las fórmulas repetitivas y, por otra parte, se conciben como una unidad enunciativa por sí mismas. Esta es la estructura que tenía el MH según se deduce de la lectura de los papiros. Debemos suponer, pues, que el lector de esta tipología de textos, de acuerdo con las convenciones del género, entendía perfectamente que el lemma suscitaba una pregunta y era capaz de reconocerla sin la fórmula introductoria. Cualquier lector conocedor de estos mecanismos entiende que la pregunta atañe al extraño término $\mu \nu \rho \mu 1 \delta o ́ v \varepsilon \sigma \sigma$. En otros escolios en los que el lemma puede ser un verso entero, la pregunta no es tan obvia a simple vista. Lo veremos a continuación con los ejemplos que analizaremos.

6 Ed. van Thiel 2014 para todas la historiae transcritas. El principio de esta historia está testimoniado también en el papiro de Florencia PSI 1505 (véase lista de papiros en el apartado siguiente). Véase Luppe 2009. 
Por consiguiente, como decíamos, no podemos clasificar el MH como un manual mitográfico simplemente, a pesar de que podría haber sido utilizado como tal. El estudio del MH debe ser abordado conjuntamente desde la mitografía y la crítica homérica.

\section{El Mythographus Homericus: estado de su transmisión textual}

Debemos tener en cuenta desde el principio que, aunque los estudiosos de finales del siglo XIX han usado el nombre de Mythographus Homericus, no hay motivos para considerarlo un autor real. Es más bien una tradición menor de exégesis homérica que se origina en el s. I d. C., si no antes, y sobrevive en los manuscritos medievales. Por lo tanto, un intento de reconstruir un arquetipo no tiene sentido. Por otra parte, el conjunto de historiae fabulares debe ser considerado un corpus único a pesar de las manipulaciones a que ha sido sometido en diferentes momentos de su transmisión. Una comparación textual entre los papiros y los escolios menores apunta hacia esta interpretación: en algunos casos, el texto es casi idéntico en el papiro y en el escolio relacionado, y en otros se ha modificado. Además, muchas historiae pueden haber sido agregadas o suprimidas durante el largo proceso de transmisión. Las razones de toda esta manipulación son un tema muy complejo que no vamos a tratar en este artículo.

El MH, pues, no se ha conservado como un texto independiente en los manuscritos medievales, pero muchas historiae fueron incorporadas a los escolios menores ${ }^{7}$. Los papiros del comentario a la Ilíada atribuido al $\mathrm{MH}$ identificados hasta la fecha son los siguientes (por orden de publicación):

1) P.Oxy. 418 ed. B. P. Grenfell, S. Hunt (The Oxyrhynchus Papyri III [Londres 1903], pp. 63-65). s. I exeunte/II ineunte.

2) P.Lond. 142 ed. H. J. M. Milne (Catalogue of the Literary Papyri in the British Museum [Londres 1927], p. 121). s. II.

3) P.Schub. 13930 ed. W. Schubart (Griechische Literarische Papyri [Berlín 1950], pp. 45-47). s. V.

7 En mi tesis doctoral (Pagès 2007) se recoge y comenta el corpus completo de las historiae correspondientes a la Ilíada, y facilita un apéndice con la transcripción de las historiae de la Odisea de la edición de Dindorf y del papiro PSI 1173. 
4) P.Berol. 13282 ed. W. Muller (Griechische literarische Texte auf Papyrus und Pergament, Forschungen und Berichte. Staatliche Museen zu Berlin, vol. X [Berlín 1968], pp. 118-119). s. III.

5) P.Oxy. 3003 ed. P. J. Parsons (The Oxyrhynchus Papyri XLII, [Londres 1974], pp. 15-19). s. II.

6) P.Hamb. 199 ed. B. Kramer (Griechische Papyri der Staats- und Universitätsbibliothek Hamburg III [Bonn 1984], pp. 25-34). s. II.

7) P.Oxy. 3830 ed. M. A. Harder (The Oxyrhynchus Papyri LVI [Londres 1989], pp. 37-44). s. II.

8) P.Oxy. 4096 ed. P. Schubert (The Oxyrhynchus Papyri LXI [Londres 1995], pp. 15-45). s. II.

9) PSI XV 1505 ed. S. Pernigotti (Papiri greci e latini. Pubblicazioni della Società Italiana per la ricerca dei papiri greci e latini in Egitto XV [Florencia 2008], pp. 190-192). s. III.

También se conserva un fragmento breve, probablemente un ejercicio escolar, en un ostracon: PSI VIII 1000 ed. P. Viereck, G. Vitelli (Papiri greci e latini. Pubblicazioni della Società Italiana per la ricerca dei papiri greci e latini in Egitto VIII [Florencia 1927], p. 209). Sus editores lo dataron en el siglo IV. Montanari ${ }^{8}$ propone una datación más alta, en el s. I o II.

Para la Odisea, hasta ahora solo se han identificado dos papiros: el papiro PSI X 1173 ed. G. Coppola (Papiri greci e latini. Pubblicazioni della Società Italiana per la ricerca dei papiri greci e latini in Egitto $\mathrm{X}$ [Florencia 1932], pp. 132-138), y P.Vind. 29784 ed. H. Gerstinger (Griechische literarische Papyri I, MPER N. S. I [Viena 1932], pp. 130-131).

Todos estos papiros atestiguan la circulación del $\mathrm{MH}$ durante la práctica totalidad del período imperial romano (siglos I a V d. C.) $)^{9}$.

El papiro de Florencia PSI 1173, del s. III, es el mejor ejemplo conservado. Permite la lectura de una sucesión de trece historiae cuyo contenido y secuencia coincide en gran parte con el de los correspondientes escolios, si bien el texto no presenta una coincidencia textual exacta. A pesar de las leves alteraciones, la comparación de los dos estadios de transmisión del texto permite apreciar una clara voluntad de conservación del contenido del MH en los escolios menores.

\footnotetext{
8 Montanari 1995a, pp. 169-170.

9 Para los papiros del MH véase Gärtner 1999; Haslam 1990; Haslam 1996; Luppe 1984, 1993, 1996, 1996b, 1996c, 1996d, 1996-1997, 1997a, 1997b, 2009; Merkelbach 1956; van Rossum-Steenbeek 1996.
} 
El conjunto completo de las historiae fabulares existentes que derivan hipotéticamente del $\mathrm{MH}$ se puede encontrar, pues, en los manuscritos de los escolios menores a la Ilíada, los llamados Escolios D (la sigla procede de Scholia Didymi, ya que fueron erróneamente atribuidos a Dídimo $)^{10}$. En lo que respecta a los escolios a la Odisea, una cantidad considerable de escolios menores catalogados por Dindorf bajo la sigla V (scholia uulgata) se encuentra diseminada en diferentes manuscritos ${ }^{11}$. Ernst (2006) emplea la sigla D (en lugar de V) también para los escolios menores a la Odisea.

\section{El Mythographus Homericus como comentario: análisis de algunos ejemplos de uso exegético de la mitografía}

Los fragmentos conservados sobre papiro son suficientes para apreciar la estructura del MH: bajo un lemma homérico se ofrece una breve explicación en forma de historia, que en la mayor de los casos es el argumento de un tema mítico. En un buen número de ellas, el relato finaliza con la llamada subscriptio, una cita que remite a un autor. Esta misma estructura se aprecia en determinados escolios menores en los que la historia aparece interpolada entre información de contenido más general procedente de otros comentarios y glosarios. Así pues, una de las características de este conjunto de narraciones míticas es que, desde el punto de vista formal, pueden considerarse un hypomnema ${ }^{12}$, es decir, un comentario de una obra antigua ${ }^{13}$ estructurado mediante lemmata cuyo objeto principal es la clarificación del pasaje citado en el lemma. Los antiguos hypomnemata se cuentan entre los principales precursores de los escolios medievales ${ }^{14}$.

10 De Marco 1932; Montanari 1979, pp. 340-341; Montanari 1995b, pp. 80-85.

${ }^{11}$ Van Rossum-Steenbeek 1998, pp. 99-101, 301-308; véase también Dindorf 1855, pp. xv-xviii; Montanari 2002, pp. 129-144; Pontani 2005, pp. 3-7; Ernst 2006, pp. v-vi.

${ }^{12}$ En castellano se usan el sustantivo exégesis y el adjetivo exegético para designar una explicación o interpretación crítica de un texto, mientras que en griego antiguo su significado no estaba

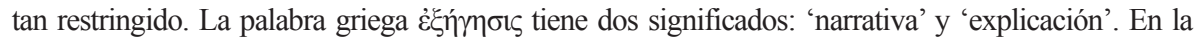

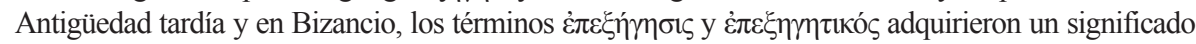
más especializado cercano a los términos exégesis y exegético, y se usaron en comentarios y tratados. En este artículo usamos exégesis y exegético de acuerdo con sus significados modernos, más cerca-

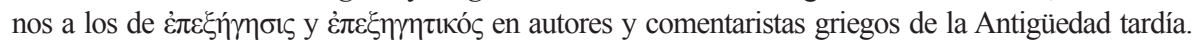

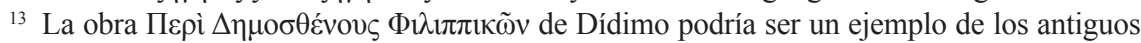
hypomnemata (Arrighetti 1977, pp. 56-59); cf. Wilson 2007, pp. 42-43; Schironi 2012, p. 402.

${ }^{14}$ El término hypomnema en época helenística e imperial era usado para referirse a anotaciones previas a la redacción de obras históricas y, secundariamente, a las obras mismas. En 
Los hypomnemata se centran en el texto mismo (gramática, lexicografía, métrica) o en los contenidos (mitología, historia, realia). En lo que respecta al $\mathrm{MH}$, el comentario puede aplicarse a una sola palabra, a un verso o incluso a un pasaje más largo. La mitografía es la base para el comentario: el comentarista proporciona narraciones míticas relacionadas con el texto comentado. Por lo tanto, a priori, podemos considerar que el MH es un comentario mitográfico, es decir, un hypomnema en el que se recurre a la mitografía para comentar los lemmata ${ }^{15}$.

El MH, tal como nos ha llegado, es predominantemente mitográfico ${ }^{16}$ en tanto en cuanto la narración mítica ocupa la práctica totalidad del texto. Cada historia es una ilustración del lemma $a^{17} \mathrm{y}$, no obstante, un buen número de ellas puede leerse per se, ya que constituye una unidad narrativa independiente en la que no aparece ninguna marca formal de comentario ni referencia explícita al lemma, tal como hemos podido comprobar en el ejemplo dado de la historia sobre los mirmidones (Sch. D a Il. I 180). Por otra parte, un número menor de historiae ofrecen una exégesis del lemma con una clara vinculación con el texto y el contexto homéricos. Si bien el planteamiento metodológico es único, no parece haber una estricta unidad de criterio en la aplicación de dicho método. Esta dualidad se aprecia ya en los testimonios sobre papiro y es, a nuestro entender, un indicio de la autoría múltiple del corpus.

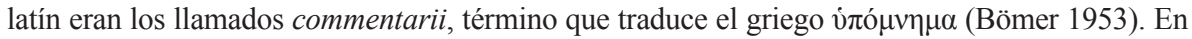
contexto exegético, sin embargo, el término adquiere un significado diferente y más restringido, y se refiere a los comentarios de obras literarias organizados por lemmata que siguen el orden de aparición en la obra objeto de comentario. Véase Arrighetti 1977, quien opone algunas objeciones a esta visión; cf. Montanari 1979, pp. 4-17; Montanari 1995b, pp. 70-71, 74-76; Wilson 2007, pp. 39-70; Nünlist 2009, pp. 9-12; Schironi 2012 passim, especialmente pp. 404-412.

${ }_{15}$ Schironi 2012, p. 407 no considera que el MH sea un hypomnema propiamente dicho, ya que un hypomnema era un comentario filológico, riguroso y profesional, sino un comentario para uso escolar a nivel elemental. Una visión muy diferente es la de Cameron (2004, pp. 273-274), que ve en el $\mathrm{MH}$ un manual mitográfico que podría haber sido consultado incluso por Ovidio para sus Metamorfosis. Ambas visiones no son incompatibles, pero no entraremos a discutir esta cuestión. La especificidad del MH quizá sea el hecho de que, si bien el hypomnema se concibe como un comentario misceláneo que aborda cuestiones diversas, el MH se centra en la tradición mítica y etiológica. No es el único caso de comentario monográfico que conocemos: se conserva el comentario astronómico a los Fenómenos de Arato de Hiparco de Nicea (Schironi 2012, p. 402).

${ }^{16}$ Para la definición, la descripción y enumeración de los rasgos que caracterizan la mitografía como género véase Fowler 2006 y Alganza Roldán 2006.

${ }^{17}$ Para la definición del término iotopí $\alpha$ en contexto exegético véase Delattre 2016. 
Para ilustrar estas afirmaciones, procedamos a un breve análisis de algunas de las historiae focalizando nuestra observación en la relación entre exégesis y mitografía, que es el tema principal de nuestro estudio.

Un buen ejemplo de comentario mitográfico es el Sch. D a Il. I 399-400

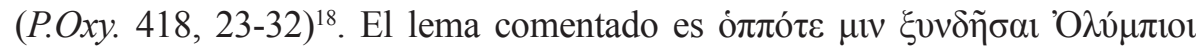

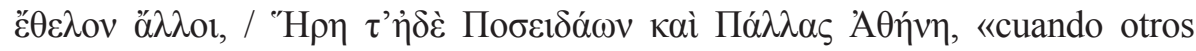
dioses del Olimpo querían encadenarlo, / Hera, Posidón y Palas Atenea». El lemma ${ }^{19}$ lo constituyen dos versos de la Ilíada en los que Homero hace una referencia a un relato mítico sin narrarlo. El MH proporciona una explicación completa como respuesta a la pregunta implícita «¿A qué se refiere Homero?».

P. Oxy. 418, 23-32 Grenfell - Hunt ${ }^{20}$

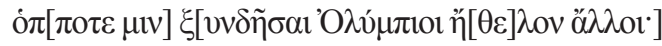

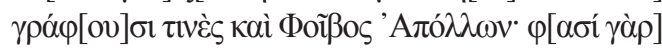

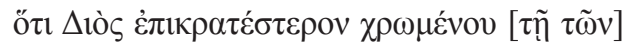

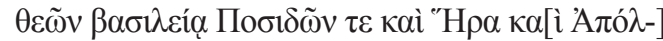

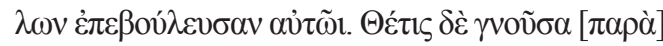

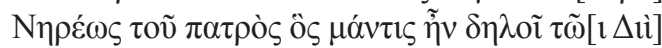

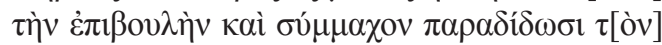

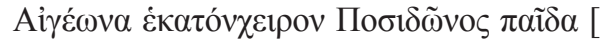

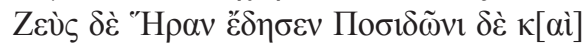

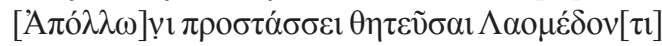

Sch. D in Il. I 399 van Thiel

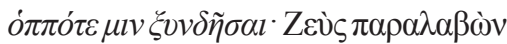

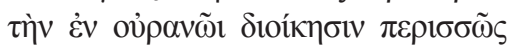

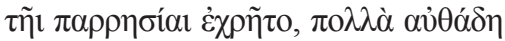

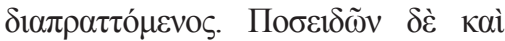

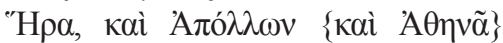

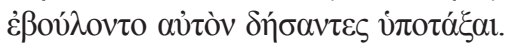

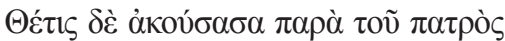

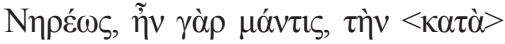

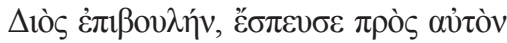

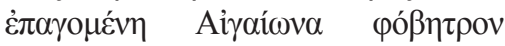

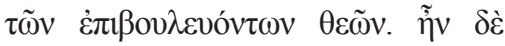

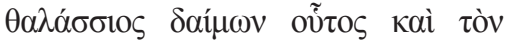

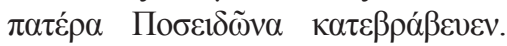

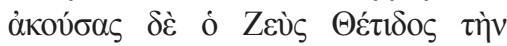

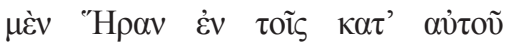

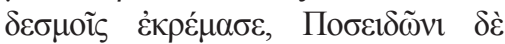

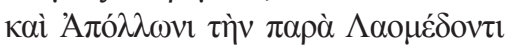

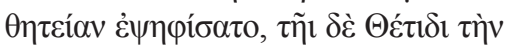

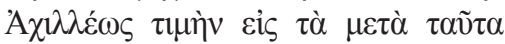

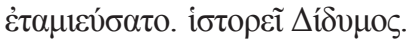

${ }_{18}$ Van Thiel 2014, p. 63; P.Oxy. 418 Grenfell - Hunt; Schmidt 1854, p. 179.

19 El lemma, como aparece en el papiro y en la mayoría de los manuscritos, es el verso

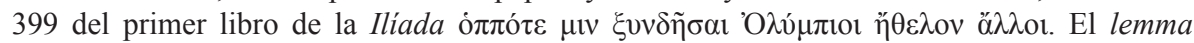
original probablemente recogía también el verso 400, por coherencia.

${ }^{20}$ En la edición del papiro (Grenfell - Hunt 1903) el lemma figura en mayúscula redonda. En nuestra transcripción usamos la cursiva (también en los ejemplos siguientes). 
La historia comienza, en el texto del papiro y el de algunos manuscritos (no en el Z, base de la edición de van Thiel), con una nota crítica sobre el

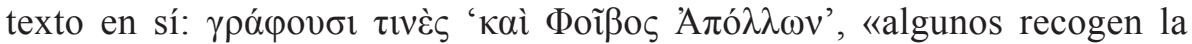

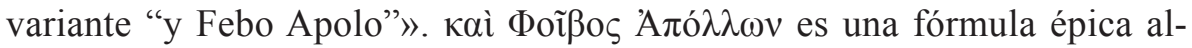

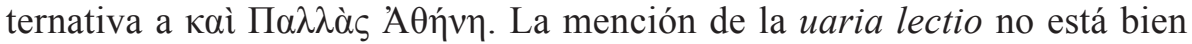
integrada en el texto. Además, este es el único caso de mención de una variante textual en todo el corpus conservado del MH. Después de esta breve nota crítica, la historia comienza ex abrupto, sin ningún vínculo conceptual ni sintáctico con el texto precedente. El lector ha de sobreentender la relación entre la nota crítica y el contenido de la historia.

Centrémonos en la forma en que el $\mathrm{MH}$ comenta a Homero en este pasaje concreto sobre la conspiración contra Zeus. El mitógrafo proporciona un resumen del mito y, al mismo tiempo, ofrece una uaria lectio que sin duda es más adecuada para esta historia. Esta es la razón por la

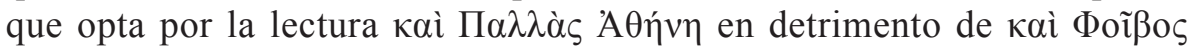
'A

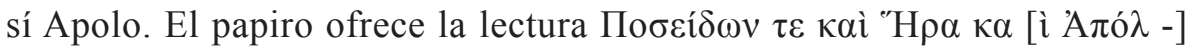
/ $\lambda \omega v \dot{\varepsilon} \pi \varepsilon \beta$ ○ó $\lambda \varepsilon v \sigma \alpha \nu \alpha \hat{\tau} \tau \tilde{\omega} 1$, «Posidón, Hera y [Apo]lo conspiraron contra

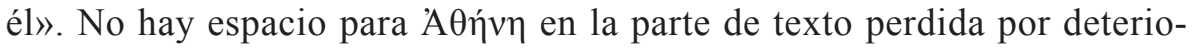
ro del papiro. Por el contrario, en los manuscritos de los escolios leemos

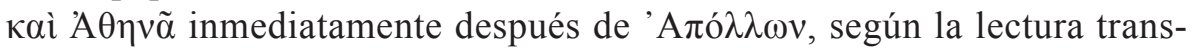
mitida por la tradición aristarquea ${ }^{21}$. Van Thiel la marca entre llaves porque no aparece en el papiro. Es lógico suponer que esta lectura se introdujo posteriormente para corregir la incoherencia que producía con la lectura de Aristarco.

En efecto, existe una clara discrepancia entre la lectura aristarquea de Homero y la fuente del $\mathrm{MH}$, que aparentemente sigue una variante atribui-

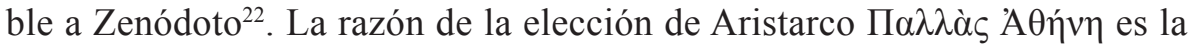
coherencia interna del relato homérico: Posidón, Hera y Atenea eran partidarios de los aqueos, mientras que Apolo apoyaba a los troyanos. Los tres dioses estaban enojados con Zeus porque había escuchado la súplica de

${ }^{21}$ La tradición crítica aristarquea ha sido transmitida por el llamado Viermännerkommentar, que sobrevive parcialmente en los Scholia Vetera; ver H. Erbse 1969, pp. LII-LVI; para este pasaje concreto: Sch. a Il. I 399; Erbse 1969, pp. 113-114. Sobre el comentario de Aristarco a la Ilíada véase la reciente monografía de Schironi 2018.

${ }^{22}$ Sch. a Il. I 400 Erbse 1969, p. 114. 
Tetis y estaba ayudando a los troyanos. El MH clarifica la historia sin tener en cuenta el análisis interno de Aristarco. Conocía la lectura de Zenódoto a través de Dídimo, a quien cita al final.

Podemos apreciar, en definitiva, la agudeza del mitógrafo y su capacidad de análisis del texto. Es capaz de valorar una uaria lectio y hacer su elección en coherencia con su objetivo. Esta es una buena ocasión para comprobar hasta qué punto la tradición exegética ha condicionado la fijación de los textos clásicos. Los editores modernos se han inclinado por la tradición aristarquea, más atenta a la coherencia interna de la obra, reservando la lectura de Zenódoto para el aparato crítico.

El segundo caso elegido para analizar es el comentario a un pasaje de la Odisea (XII 59-73; Sch. V in Od. XII 70; papiro PSI 117323). El lemma en el papiro es el verso 70 del canto XII (excepto la última palabra,

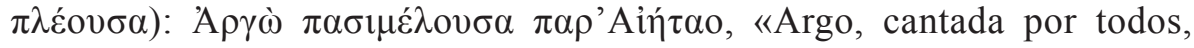
cuando regresaba del país de Eetes». Según Homero, que pone en boca de Circe las advertencias a Odiseo, solo la nave Argo pudo pasar por el

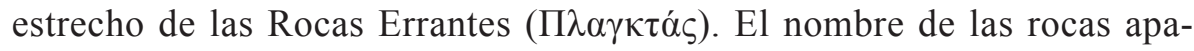
rece antes, en el verso 61, y en el 73 se menciona a Jasón. De hecho, Homero hace una relativamente extensa referencia al mito de los Argonautas. Pero tan solo menciona la parte del mito que le interesa evocar: el peligro de las Errantes, la nave Argo y la protección de Hera que permitió a Jasón franquear el peligro. El MH elige como lemma, de todo el pasaje homérico, el verso 70, que menciona la nave Argo (a la que califica de $\pi \alpha \sigma 1 \mu \varepsilon ́ \lambda o v \sigma \alpha$, 'cantada por todos') y el regreso desde el país de Eetes. El relato del $\mathrm{MH}$ responde a las tres preguntas que suscita el lemma: ¿por qué la nave Argo era «cantada por todos»? ¿Cómo consiguió superar el paso de las Errantes? ¿Quién era Eetes? ¿Por qué la nave Argos regresaba del país de Eetes? Ofrecemos el texto de la historia conservada en el papiro y el escolio correspondiente:

\footnotetext{
${ }^{23}$ fr. 5re. $117-120$, 5ue. $121-136+$ fr. 6re. 137-147 Coppola.
} 
PSI 1173 fr. 5-6 117-147 Coppola

fr. 5re.

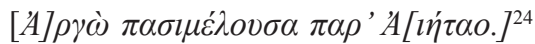

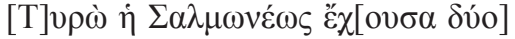

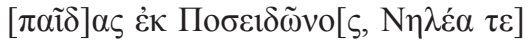

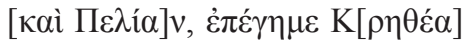

fr. 5ue.

] $1 \alpha \delta[$

$\pi \varepsilon ́ \mu \pi] \varepsilon 1 \pi \alpha \rho \dot{\alpha} \mathrm{X}[\varepsilon i ́ \rho \omega \nu] \alpha[[\pi \alpha \rho[*]]$

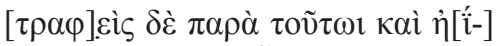

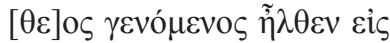

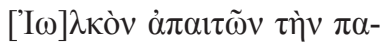

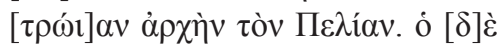

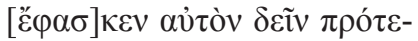

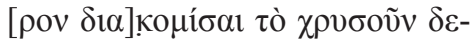

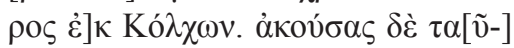

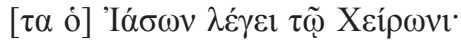

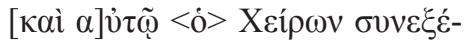

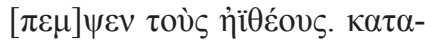

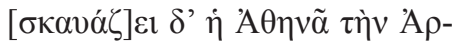

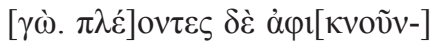

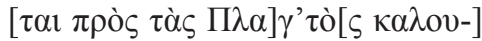

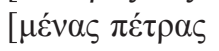

fr. 6 re.

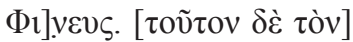

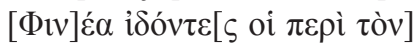

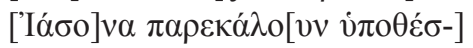

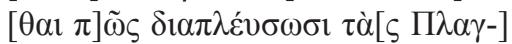

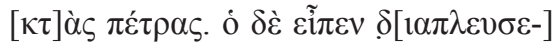

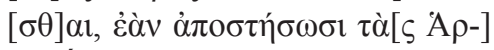

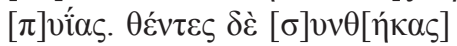

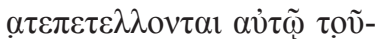

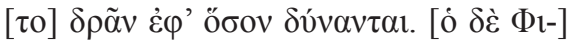

Sch. D in Od. XII 70 Ernst

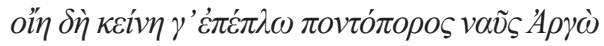

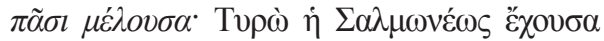

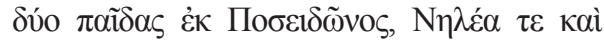

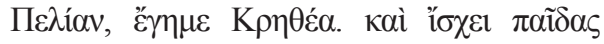

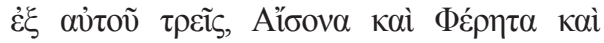

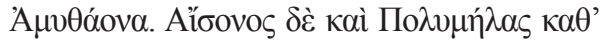

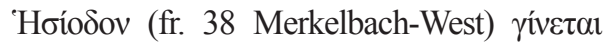

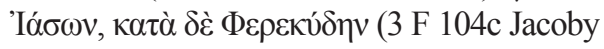
$=$ fr. $104 \mathrm{c}$ Fowler) $\left.\grave{\varepsilon}^{\xi}{ }^{\prime} A \lambda \kappa \mu \varepsilon \dot{\delta}\right\rangle \varsigma . \tau \varepsilon \lambda \varepsilon v \tau \tilde{\omega} \nu \delta \grave{\varepsilon}$

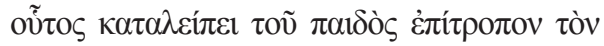

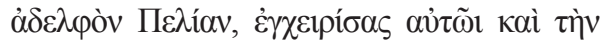

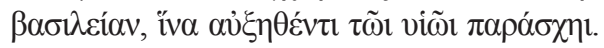

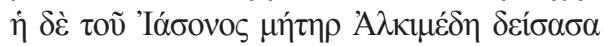

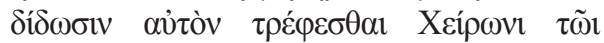

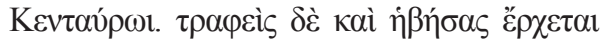

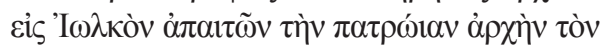

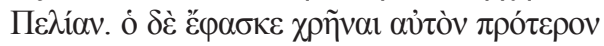

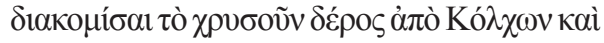

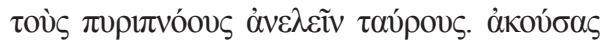

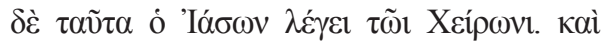

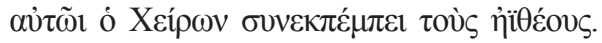

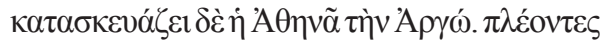

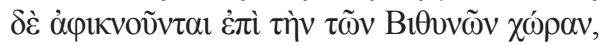

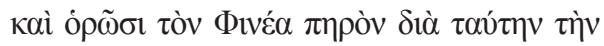

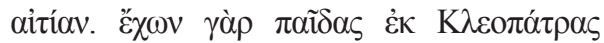

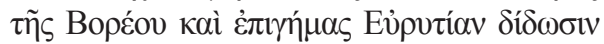

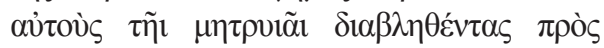

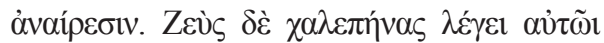

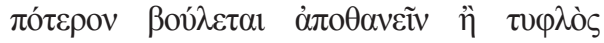

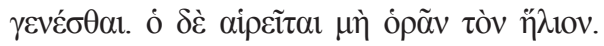

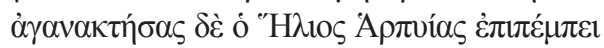

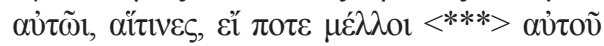

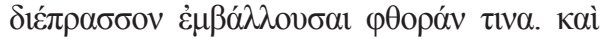

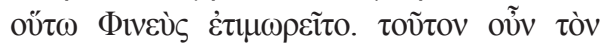

${ }^{24}$ Od. XII 70. En la edición de Ernst el lemma se indica en negrita. Nótese que el lemma es el verso 69 y la primera mitad del 70 (en el códice $M$, mientras que en el $\mathrm{Z}$ es tan solo 


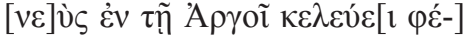

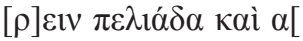

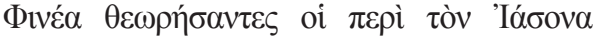

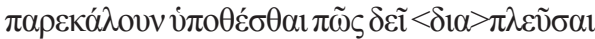

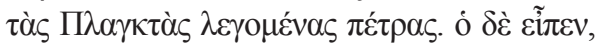

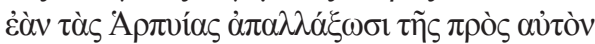

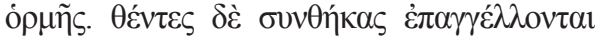

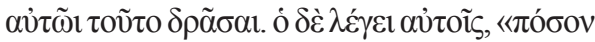

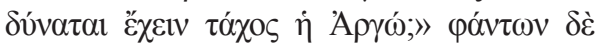

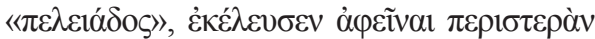

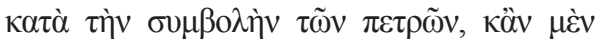

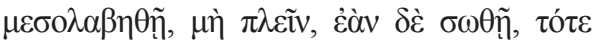

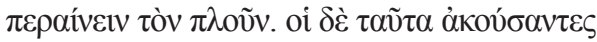
$\pi$ oเoṽ

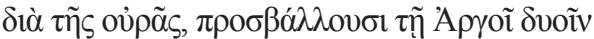

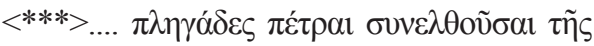

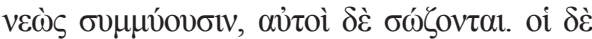

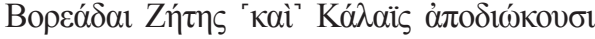

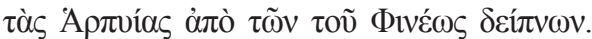

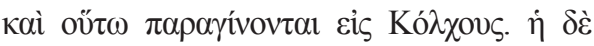

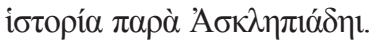

El relato del $\mathrm{MH}$ parte del nacimiento de Neleo y Pelias y facilita una breve genealogía hasta Jasón, protagonista del mito. Después narra los motivos de la expedición de los Argonautas y, de forma muy sintética, el viaje hasta la llegada a Yolcos. Pontani ${ }^{25}$, a partir de una lectura del ms. Marc. gr. IX.29, que conserva la versión latina de la Odisea de Leoncio Pilato, con algunos escolios in margine, ha sugerido la posibilidad de que este escolio provenga de la fusión de dos escolios independientes. $\mathrm{Su}$ inusual extensión podría constituir un indicio de ello. Aun así, adviértase que en el papiro PSI 1173 ya aparecen en una única historia. La hipótesis de Pontani supondría la consulta de un códice en el que la información estuviera recogida en dos historiae distintas bajo sus respectivos lemmata. El relato sobre Fineo podría ser una exégesis a la misteriosa referencia homérica a las palomas bajo el

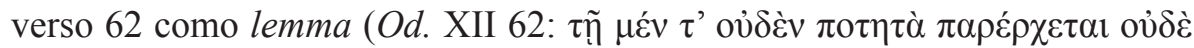
$\pi \varepsilon ́ \lambda \varepsilon(\alpha \imath)$. El motivo de la paloma, sin duda la etiología de una práctica mari-

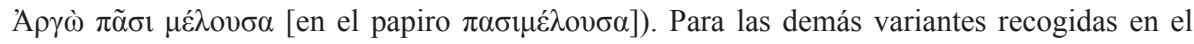
aparato crítico véase la edición de Ernst (2006).

${ }^{25}$ En Pagès y Villagra (en preparación). 
nera, se expone en el texto en forma de relato: Fineo aconseja a Jasón dejar volar una paloma antes de pasar las Errantes. Pero este orden en los escolios invierte la secuencia narrativa, ya que el viaje de Jasón se expone bajo el verso 70 como lemma, en el que se menciona la nave Argo. La transmisión textual, pues, habría fusionado dos historiae originariamente independientes para crear un relato unificado y coherente. La hipótesis de Pontani es lúcida y convincente, pero se basa en una traducción latina muy tardía ${ }^{26}$.

Sea como fuere, la lectura del largo escolio sugiere dos partes claramente diferenciadas: por una parte la genealogía de Jasón y los motivos de su viaje y, por otra, el relato del viaje, del que tan solo se relatan dos episodios, el de Fineo y las Harpías y el del paso de las Simplégades. La omisión de los demás episodios se justifica por el uso exegético del resumen del mito: Fineo fue quien reveló a Jasón la existencia de las Simplégades y la manera de franquearlas. La referencia a la paloma es especialmente significativa, en tanto en cuanto Homero se refiere explícitamente a este animal y al rito que se practicaba en el paso de las Errantes. Desde este punto de vista los demás episodios son irrelevantes. La elección de motivos parece, pues, justificada y coherente desde el punto de vista exegético y, si bien es habitual que las historiae proporcionen relatos relativamente completos a pesar de que el lemma se refiera solo a una parte o a un motivo concreto, en este caso la extensión de la narración parece haber sugerido una selección adecuada al paso comentado.

A pesar de la coherencia metodológica que acabamos de apreciar, el mitógrafo parece no percatarse de que en el texto homérico la nave Argo pasó las Errantes (Planctae), no las Simplégades y, además, en su viaje de regreso

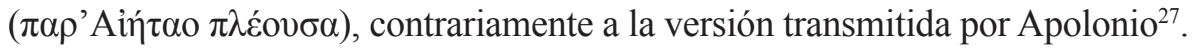
El relato que nos ofrece, pues, entra en contradicción con las propias palabras de Homero. El mitógrafo nos facilita un resumen parcial de la versión más divulgada, que coincide grosso modo con el relato de Apolonio, autor al que, sorprendentemente, no cita, y que discrepa de Homero. El autor citado en la

${ }^{26}$ Consideramos prudente esperar hasta la publicación de Pontani de los escolios del canto XII de la Odisea antes de tomar posición ante una cuestión tan incierta.

${ }^{27}$ La identificación entre Simplégades y Planctae es antigua, a pesar de que no parece que Homero y Apolonio se refieran al mismo lugar; en efecto, la especulación antigua sobre la localización de la toponimia mítica no pudo hallar una lógica convincente al respecto. El debate es antiguo (Str. I 2.10; III 2.12; III 5.5; Sch. in E., Med. 2; Sch. in Lyc., Al. 1285 Scheer). Véase Seaton 1887; Sinatra 2003, pp. 90-92. 
subscriptio es Asclepíades. Es probable que el mitógrafo haya consultado un resumen de una tragedia sobre Fineo en los Tragodumena de Asclepíades ${ }^{28}$.

Esta superficialidad y ausencia de crítica que apreciamos en este ejemplo contrasta con el caso anterior. Si bien hemos observado como el redactor de la historia de la confabulación contra Zeus manifestaba la competencia suficiente como para valorar la conveniencia de una determinada opción entre dos variantes textuales y la ajustaba a su relato sin entrar en contradicción con el pasaje homérico, el redactor del segundo caso analizado no es capaz de apercibirse de su incoherencia. La comparación entre estos dos casos demuestra la autoría múltiple del comentario, o, al menos, que el redactor del comentario de la Ilíada y el de la Odisea no fueron el mismo.

A pesar de la diferencia que acabamos de apreciar, existe una unidad de método y objetivo compartida por ambos redactores: el texto es un comentario de un pasaje homérico basado en la trama de un mito relatada de forma lineal, concisa y desnuda de cualquier tipo de ornato, según los esquemas establecidos por el género mitográfico ${ }^{29}$. Esta unidad de método se aprecia en todo el corpus, tanto en los testimonios sobre papiro como en las versiones conservadas en los escolios. Para ahondar en el análisis procederemos a la lectura atenta de otros ejemplos significativos.

El tercer caso seleccionado para nuestro estudio es la historia contada en

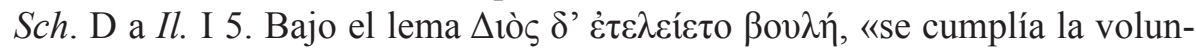
tad de Zeus». No hay rastro de esta historia en los papiros, pero en los escolios $\mathrm{D}$ podemos leer un texto completo y coherente (edición de van Thiel, en cursiva el lemma y la parte atribuible, según nuestro criterio, al $\mathrm{MH}$ ):

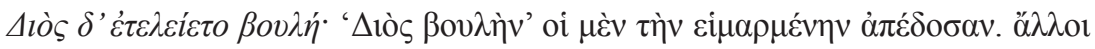

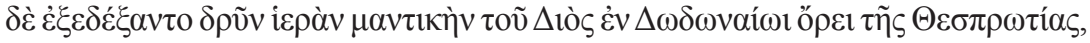

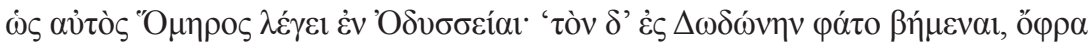

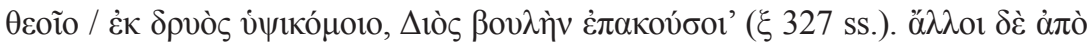

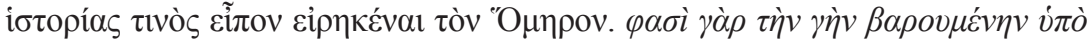

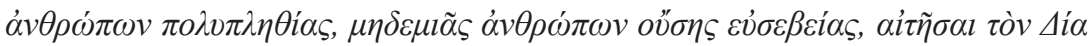

${ }^{28}$ Villagra 2012, pp. 17, 178-184. El contraste de fuentes que recoge el texto del escolio (no la historia del papiro) probablemente figuraba en el texto de Asclepíades, por lo que no es necesario suponer que el mitógrafo haya realmente consultado a Hesíodo y a Ferecides, autores citados en el escolio.

${ }^{29}$ Fowler 2006, pp. 37-43. 


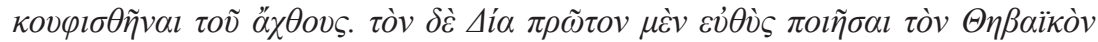

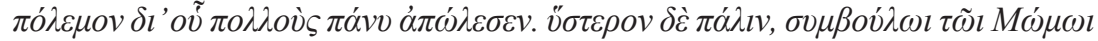

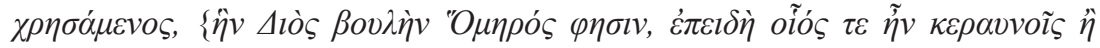

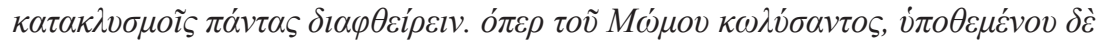

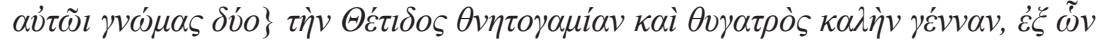

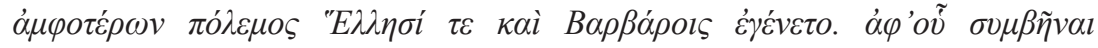

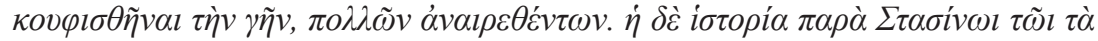

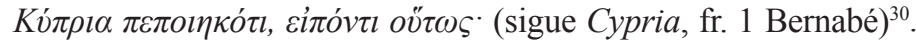

Debemos tener en cuenta que no todo el texto de este escolio es atribuible al $\mathrm{MH}$, ya que presenta varios comentarios que provienen de diferentes fuentes se-

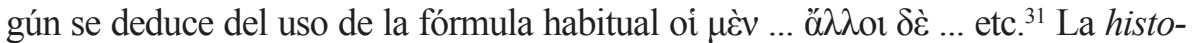

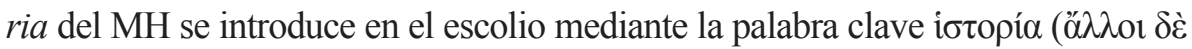

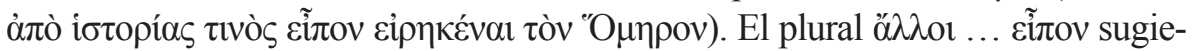
re que el escoliasta conoce más fuentes que transmiten el relato, empezando por los mismos Cantos Ciprios que el escoliasta cita textualmente. No podemos saber si la cita textual ya figuraba en el $\mathrm{MH}$ o fue una adición del escoliasta. Montana$\mathrm{ri}^{32}$ ha señalado que estas largas citas podrían haber sido habituales en el $\mathrm{MH}$ original y que la tradición manuscrita las podría haber suprimido. Como consecuencia, la mayoría de las historiae terminan con la mención de un autor antiguo o, a veces incluso, el nombre del autor y el título de una obra. De hecho, solo hay otra historia con una larga cita textual, la de Ceneo en el Sch. D a Il. I $264^{33}$.

La historia incluida en este escolio responde a la pregunta «¿a qué se refiere Homero con las palabras la voluntad de Zeus?» La respuesta que nos da es que las guerras tebana y troyana fueron el resultado de la voluntad de Zeus, que cumplía un juramento dado a Gea, la Tierra, para aliviar la carga de llevar a la humanidad, que había proliferado en demasía ${ }^{34}$.

${ }^{30}$ El texto del escolio continúa con la interpretación de Aristarco y Aristófanes de Bizancio.

31 Van Thiel 2014, p. 21; Pagès 2005.

${ }^{32}$ Montanari 1995a, p. 156.

${ }^{33}$ P.Oxy. 418.9-22; Montanari (nota anterior). En el papiro, que es el mismo que contiene la historia analizada de la conspiración contra Zeus, no se conserva la cita textual de Apolonio. No podemos saber si el papiro es una copia en epítome o si los versos de Apolonio fueron incorporados más tarde a la tradición manuscrita de los escolios.

${ }^{34}$ El mitógrafo retoma un motivo testimoniado por un pasaje paralelo en el Mahabharata indio (1.58, 35 ss.). Véase De Jong 1985; Burkert 1987, p. 100; Vieille 1998. La coincidencia 
El relato resumido en este escolio proporciona una explicación del contexto mítico que, aunque no es esencial para comprender el pasaje citado en el lema, permite una comprensión más profunda de este (de acuerdo con los criterios del $\mathrm{MH}$ ). Su objetivo exegético es obvio, ya que el texto de la historia hace una referencia explícita al texto de Homero cuando dice îv $\Delta$ iò

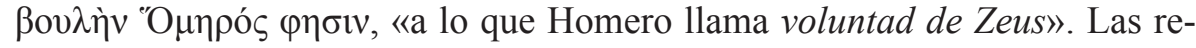
ferencias explícitas al texto homérico son muy esporádicas en el corpus conservado, pero podemos afirmar que son una característica original, ya que el papiro de Oxirrinco 4096, del s. II, da fe de ello ${ }^{35}$.

La relación entre la Ilíada y los Cantos Ciprios en este pasaje concreto es un claro ejemplo de lo que se ha llamado la naturaleza metacíclica de la poesía homérica $^{36}$. Homero probablemente alude a un motivo de los Cantos Ciprios. El público de la poesía homérica en el período arcaico podía reconocer esas referencias cruzadas y las relaciones de intertextualidad entre diferentes poemas. En épocas posteriores, los comentaristas proporcionarían una explicación de esta interrelación que los lectores ya no sabían establecer.

Procedamos al análisis de un cuarto caso. El ejemplo elegido es la historia sobre Heleno (Sch. D a Il. VII 44) ${ }^{37}$, también atestiguada por el papiro de Oxirrinco $3830^{38}$. El fragmento sobre el papiro comienza, como es habitual, con el lemma de la Ilíada, con las palabras comentadas, seguido del texto de la narración mítica, y concluye con una subscriptio que remite a Anticlides:

P.Oxy. 3830 fr. 1 + fr. 2 col. 1, 2-13 $\operatorname{Harder}^{39} \quad$ Sch. D a Il. VII 44 van Thiel

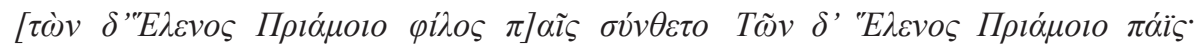
$\theta v \mu[\tilde{\omega} l \cdot \mu v-]$

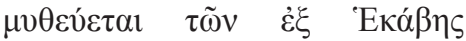

del motivo no implica coincidencia del patrón narrativo. El relato indio no ofrece más paralelos en lo que respecta a la secuencia de motivos narrativos, como demuestra De Jong en el artículo citado. No es necesario, pues, postular una dependencia o una influencia oriental clara. Podría tratarse de un motivo universal (Bernabé 1979, p. 106, n. 19).

${ }^{35}$ P.Oxy. 4096 fr. 5 col. 1, 13-14 Schubert; Pagès en Pagès y Villagra (en preparación).

${ }^{36}$ Tsagalis 2011, passim, especialmente pp. 218-219.

37 D-Scholia van Thiel, p. 307; P.Oxy. 3830 Harder; Luppe 1993; van Rossum-Steenbeek 1998, p. 50.

${ }^{38}$ Fr. 1 + fr. 2 col. 1, 2-13 Harder; Luppe 1993.

${ }^{39}$ En el texto de la historia se marcan en cursiva las propuestas de restitución de Luppe (1993). 


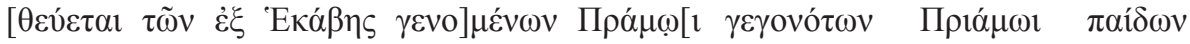
$\pi \alpha i ́ \delta \omega v]$

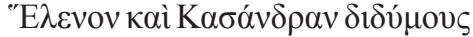

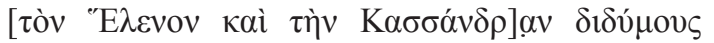
$\gamma[\varepsilon \gamma \varepsilon v \tilde{\eta}-]$ $\gamma \varepsilon \gamma \varepsilon v v \tilde{\eta} \sigma \theta \alpha$. $\tau \tilde{\omega} v$ $\delta \dot{\varepsilon} \gamma \varepsilon v \varepsilon \theta \lambda i ́ \omega v$

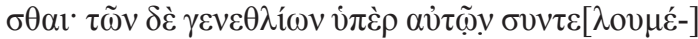

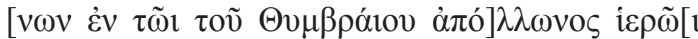
$\tau o \grave{s} \varsigma]$

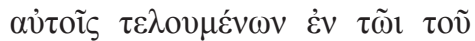

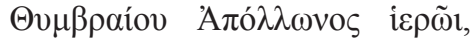

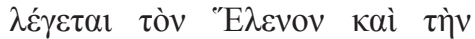

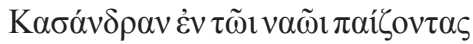

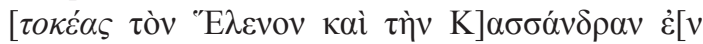
$\tau \tilde{\omega} l v \alpha-]$

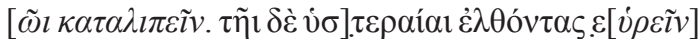

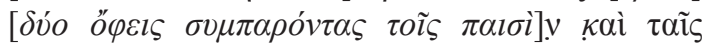
$\gamma[\lambda \omega ́ \sigma-]$

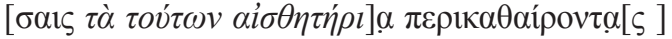
oi] $\delta \dot{\varepsilon}$ ö $\varphi \varepsilon i \tilde{\varsigma} \varepsilon \dot{\theta} \theta \dot{\varepsilon} \omega[\varsigma$ $\varepsilon i \varsigma$ ]

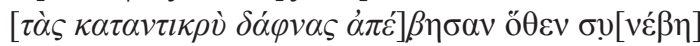

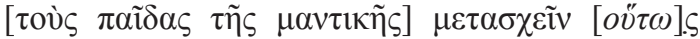

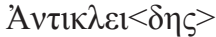

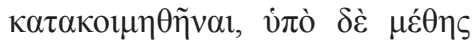

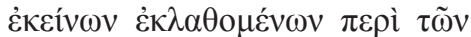

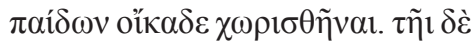

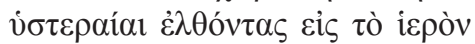

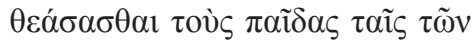

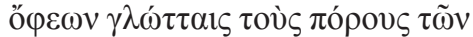

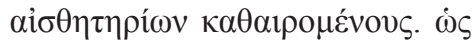

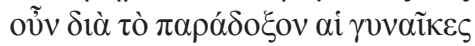

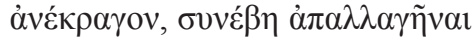

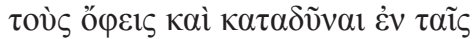

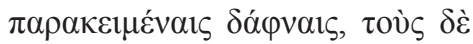

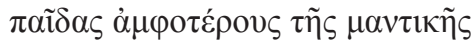

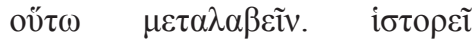

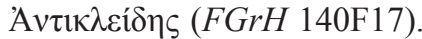

En esta historia podemos ver otro ejemplo de lo que se puede llamar

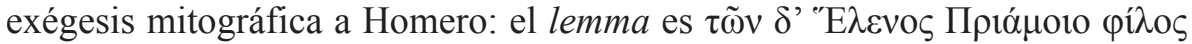
$\pi \alpha i ̃ \varsigma ~ \sigma u ́ v \theta \varepsilon \tau o ~ \theta v \mu \tilde{\omega}$. En mi opinión, el siguiente verso debe tenerse en cuenta

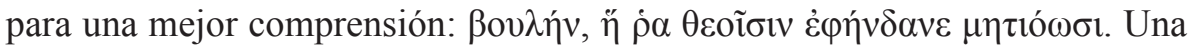
traducción de ambos versos sería «Heleno, hijo querido de Príamo, entendió el plan que había complacido a los dioses que lo habían concebido». La historia contada por el MH explica el origen de la facultad oracular de Heleno. El texto resume el mito de Casandra y Heleno, a quienes Apolo otorgó el don de la profecía. El motivo no aparece en los poemas homéricos. La exégesis consiste, pues, en una ampliación contextual; como ya se ha dicho, la audiencia de las recitaciones épicas ya conocía el contexto mítico de la Ilíada pero en época imperial este debía de ser ya lejano y desconocido para los lectores que se iniciaban en la lectura de los poemas homéricos. Comentarios como el del MH daban respuesta a esa necesidad. El lector del escolio aprende no solo que Heleno era un vidente, sino también cómo obtuvo su facultad. Como podemos ver, el texto dado por el comentarista es más que una mera exégesis, 
ya que no es necesario el relato de Heleno y Casandra desde el principio para comprender que Homero se refiere al hecho de que Heleno fuera un vidente. No solo hay una respuesta a la pregunta hipotética «¿de qué está hablando Homero?», a saber, «¿cómo podía Heleno entender el acuerdo tomado por los dioses?», sino también una expansión narrativa que proporciona una respuesta a la pregunta «ipor qué Heleno era un vidente?».

Los cuatro ejemplos analizados hasta ahora nos dan una idea de la naturaleza de esta tradición mitográfico-exegética que conocemos como MH: el breve resumen de un mito relacionado con un lemma homérico ofrece la posibilidad de una comprensión más profunda de un pasaje en los poemas homéricos vinculando los textos homéricos a otras obras, estableciendo una relación de intertextualidad entre Homero y otras fuentes literarias como el ciclo épico, la poesía lírica, los primeros mitógrafos y la poesía helenística.

\section{Comentario de términos específicos}

En no pocas historiae, el interés por el mito per se lleva al mitógrafo a expandir el comentario hacia un relato más completo, como hemos visto claramente en los casos analizados. La mitología genera interés por sí misma, y los contenidos proporcionados por el texto van más allá de la información estrictamente necesaria para el comentario.

De hecho, un buen número de historiae actúan como glosas ${ }^{40}$, es decir, notas sobre un solo término del lemma. Incluso cuando se cita un verso completo en el lemma, como se da en algunos papiros y, hasta cierto punto, en los códices medievales, el foco de la explicación es a menudo un topónimo, la epiclesis de un dios o el nombre de un héroe. En estos casos, deberíamos considerar la historia como una nota ilustrativa en lugar de un comentario de texto propiamente dicho y, de hecho, nos hallamos ante una concepción diferente de lo que es un hypomnema.

El rico papiro de Florencia PSI 1173 ofrece una serie de ejemplos de ambos tipos de comentario. Aparte del caso ya analizado sobre la nave

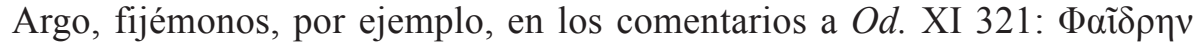

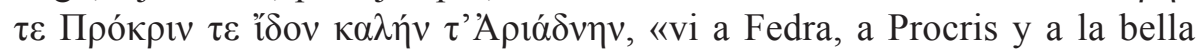

\footnotetext{
${ }^{40}$ Montanari 1995b, pp. 71-72.
} 
Ariadna». De las dos primeras heroínas mencionadas el poeta tan solo nos da el nombre. A la tercera le dedica además los versos 322-325, en los que rememora cómo Teseo se llevó a Ariadna a Atenas, y cómo la princesa murió a manos de Ártemis en la isla de Día por las acusaciones de Dioniso. El mito de Teseo y Ariadna se cuenta en detalle en el escolio (en el papiro solo se conserva la parte central del relato), desde la partida de Teseo de Atenas hasta su regreso, con el motivo omitido por Homero del abandono de Ariadna en Naxos por orden de Atenea. El relato del MH acaba con una interpretación del motivo de la muerte de Ariadna, que sin duda debía lla-

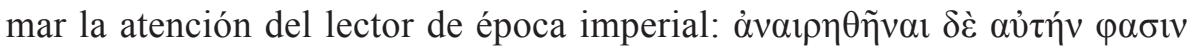

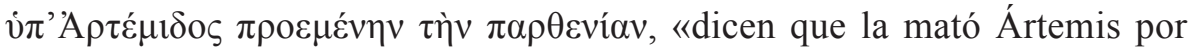
haber perdido la virginidad».

Sobre Fedra y Procris, a quienes Homero tan solo menciona, el MH nos ofrece un relato completo de sus respectivos mitos, con la misma profusión de detalle. Así pues, los dos tipos de comentario coexisten incluso en el mismo verso comentado, y están testimoniados en un mismo papiro. La función del $\mathrm{MH}$ parece ser no solo clarificar las referencias parciales de Homero a un determinado mito, sino también ilustrar las simples menciones de personajes.

En el escolio D a $\mathrm{Il}$. VII $86^{41}$ podemos apreciar un caso curioso de exégesis. En el lemma se menciona el topónimo Helesponto. MH ofrece un resumen relativamente largo del mito de Atamante y sus hijos Frixo y Hele, mito que no tiene, de hecho, absolutamente nada que ver con el pasaje comentado de la Ilíada. Es simplemente una digresión etimológica sobre el nombre compuesto Helles-pontos, «El mar de Hele». De ahí la historia, que da una respuesta a la pregunta implícita «¿Quién era Hele?» a pesar de que este personaje no aparece en absoluto, no solo en este pasaje, sino en toda la Ilíada. El comentarista no explicita que está comentando una etimología. Se centra simplemente en facilitar el mito que le da sentido, y deja que el lector supla dicha omisión. Como vemos, esta historia no ofrece ninguna información clarificadora sobre el pasaje homérico. Simplemente parece satisfacer la eventual curiosidad cultural de los lectores de la Ilíada.

${ }^{41}$ D-Scholia (van Thiel 2014), 309; P.Oxy. 3830 (Harder). 
Hay un buen número de historiae de esta clase tanto en los papiros como en los escolios. Citemos algunos ejemplos ${ }^{42}$ :

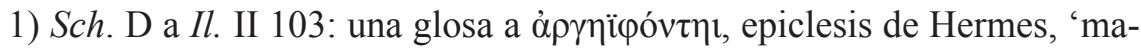
tador de Argos'. El comentarista mitógrafo continúa contando el mito incluso cuando ya se ha facilitado la etimología.

2) Sch. D a Il. II 145: bajo el lema Пóvтov 'Iкapíoı, se cuenta brevemente el mito de Ícaro, con una referencia a Filostéfano y los Aetia de Calímaco en la suscriptio.

3) Sch. D a Il. II 157: el origen mítico de la égida como explicación de la

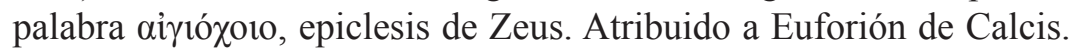

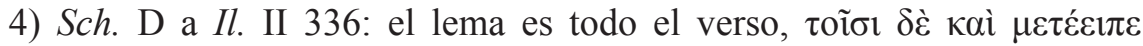

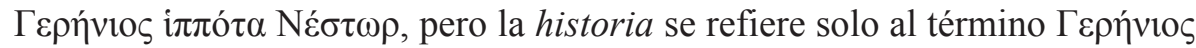
como explicación del origen de este apelativo.

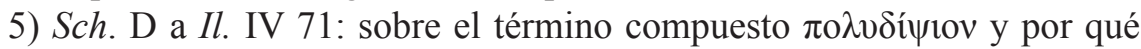
Argos fue llamado así.

6) Sch. D a Il. VI 396: mito fundacional de Teba Hipoplacia después de una mención de Eeción, padre de Andrómaca. Referencia a Dicearco.

7) Sch. D a Il. XII 231: filiación de Polidamante, cuyo padre era uno de los sacerdotes de Delfos. El lector puede sorprenderse de que el hijo de un sacerdote délfico viviera en Troya, por lo que la historia cuenta la migración de Pántoo de Delfos a Troya, donde se casó con una mujer troyana. La historia parece ser una explicación del epíteto patronímico de Polidamante Panthoïdes, a pesar de que tal patronímico no aparece en el lemma ${ }^{43}$.

8) Sch. D a Il. XII 307: bajo una mención de Sarpedón se cuenta el rapto de Europa. Vale la pena señalar que la presencia de este relato en este pasaje es muy forzada, ya que la relación entre el lemma (todo el verso) y la historia es realmente muy laxa. Hesíodo y Baquílides se citan al final.

9) Sch. D a Il. XIII 459: una simple mención de Eneas en el lemma proporciona un pretexto para contar el mito de la migración del héroe a Italia después de la caída de Troya.

10) MH a Il. XVIII 319 (P.Oxy. 4096 fr. 2, col. 1, 3-15): esta historia no se ha transmitido entre los escolios, solo está atestiguada en papiro. Es una

\footnotetext{
${ }^{42}$ Las referencias a los escolios D remiten siempre a la edición de van Thiel 2014.

${ }^{43}$ La primera aparición de este término en la Ilíada es en XIII 756.
} 


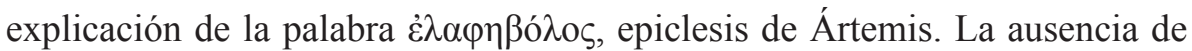
Ártemis en el pasaje citado es sorprendente: Homero se está refiriendo a cualquier cazador de ciervos.

\section{Conclusión}

Después de nuestro análisis llegamos a la conclusión de que el MH combina dos tipos diferentes de hypomnema: a) un comentario sobre el texto homérico centrado en el contenido del pasaje citado en el lema, y b) una glosa a un único término del lema independientemente del contenido del pasaje donde aparece. En el primer caso existe una relación clara entre el pasaje al que se refiere el lemma y la historia y una voluntad deliberada de clarificarlo. En el segundo se ofrece un excurso motivado por un nombre recogido en el lemma $\mathrm{y}$ el resumen de un mito sugerido por el texto homérico aunque tal información quede desvinculada del relato de Homero.

En ambos casos existe un gran interés en las tramas míticas ya que, incluso en el primero, se cuenta el mito en detalle y se brinda mucha información más allá de lo estrictamente necesario. Como hemos visto en los ejemplos evaluados, algunas historiae actúan como comentarios sobre el texto y, al mismo tiempo, proporcionan un contexto mítico más amplio. En el segundo caso los lemmata parecen actuar como entradas de un glosario.

El valor exegético del MH es innegable, a pesar del acento que ha puesto la crítica moderna en su condición de manual mitográfico. Si bien los mecanismos de comentario no se explicitan a la manera habitual de los escolios, a saber, con fórmulas que establecen una relación explícita entre lemma (objeto referenciado) e historia (referencia), el redactor ofrece un resumen completo que ilustra el contexto y suple los silencios de Homero. El lector era sin duda consciente de la función exegética de las historiae y buscaba en el MH un comentario, y no uno de los numerosos manuales mitográficos al uso. Dichos manuales se estructuraban según otros criterios. La consulta de una tradición mítica concreta debía ser mucho más asequible mediante libros estructurados por genealogías, temáticas o criterios formales como el orden alfabético. El lector del MH buscaba conocimientos sobre el contexto mítico de los poemas homéricos, sobre los personajes a los que Homero hace referencia y sus mitos, sobre etiología y sobre vinculaciones con otras tradiciones paralelas y relatos curiosos en torno a referencias concretas de los textos 
homéricos. Esta parece ser la función y el objetivo de esta obra ${ }^{44}$. Esta unidad en la concepción del texto se mantiene inalterada, por lo que podemos apreciar de la lectura de los papiros, que cubren un período de cinco siglos, y de la pervivencia de las historiae en los escolios, a pesar de algunas incoherencias que pueden apreciarse debidas a la intervención de múltiples manos.

En efecto, las oscilaciones de criterio y de competencia exegética que hemos podido apreciar sugieren la participación de diferentes redactores. Puede haberse producido una manipulación del texto desde su fase inicial de transmisión, que habría facilitado la incorporación o supresión de historiae, o la adaptación a nuevos formatos. Tal vez el MH no fuera una única obra de consulta sino un método y formato determinados. En cualquier caso, la riqueza y unidad del corpus de comentarios mitográficos a Homero que se lee en los fragmentos papiráceos y, sobre todo, en los escolios, demuestra el interés por la recopilación de todo este material, su copia en ejemplares que circularon con profusión durante todo el período imperial (a juzgar por el número de testimonios sobre papiro) y un afán por su conservación que promovió la inclusión del corpus en los escolios menores.

\section{BiBLIOGRAFÍA}

Alganza Roldán, M. (2006): «La mitografía como género de la prosa helenística: cuestiones previas», Flor. Il. 17, pp. 9-37.

Arrighetti, G. (1977): «Hypomnemata e Scholia; alcuni problemi», MPhL 2, pp. 49-67.

Bernabé, A. (ed.) (1979): Fragmentos de épica griega arcaica, Madrid.

Bömer, F. (1953): «Der Commentarius. Zur Vorgeschichte und literarischen Form der Schriften Caesars», Hermes 81 (2), pp. 210-250.

Burkert, W. (1987): The Orientalizing Revolution: Near Eastern Influence on Greek Culture in the Early Archaic Age, Cambridge (MA)-Londres.

Cameron, A. (2004): Greek Mythography in the Roman World, Oxford.

${ }^{44}$ No entraremos en el debate sobre el público al que un libro de estas características iba dirigido. Baste decir que, si bien Schironi (2012) ve tan solo un manual destinado a maestros y rhetores, ya desde Cameron (2004) se supone un público más amplio, lo que no descarta su uso escolar. Es interesante la reciente tesis de Villagra (Pagès y Villagra, en preparación), según la cual algunas omisiones y leves alteraciones en el contenido de los relatos que se perciben tras la comparación de versiones diferentes podrían ser debidas a adaptaciones de un mismo texto a usos y públicos diferentes. 
De Jong, J. W. (1985): "The Over-Burdened Earth in India and Greece», en Bender, E. (ed.), Indological Studies Dedicated to D. H. H. Ingalls, JAOS 105 (3), pp. 397-400.

Delattre, C. (2016): «Référence et corpus dans les pratiques de commentaire. Les emplois de historia», RPh 90 (2), pp. 89-110.

De Marco, V. (1932): «Sulla tradizione manoscritta degli ‘Scholia Minora’ all'Iliade», en Atti della Reale Accademia Nazionale dei Lincei 1931, Serie sesta, vol. IV, Roma, pp. 373-407.

Dickey, E. (2007): Ancient Greek Scholarship, Oxford.

Diller, A. (1935): «The Text History of the Bibliotheca of Pseudo-Apollodorus», TAPhA 66, pp. 296-313.

Dindorf, W. (ed.) (1855): Scholia Graeca in Homeri Odysseam ex codicibus aucta et emendata, vols. I-II, Oxford (reimp. Ámsterdam, 1962).

Erbse, H. (ed.) (1969): Scholia Graeca en Homeri Iliadem (Scholia Vetera), vol. I, Berlín.

Ernst, N. (ed.) (2006): Die D-Scholien zu Odyssee. Kritische Ausgabe, Colonia.

Fowler, R. (2006): «How to Tell a Myth. Genealogy, Mythology, Mythography», Kernos 19, pp. 35-46.

Gärtner, T. (1999): «Zum Geschick der Pleiade Elektra im sogenannten Mythographus Homericus (Pap. Ox. 4096) und bei Quintus von Smyrna», ZPE 124, pp. 22-24.

Haslam, M. (1990): «A New Papyrus of the Mythographus Homericus», BASP 27, pp. 31-36.

Haslam, M. (1996): «On P. Oxy. LXI 4096, Mythographus Homericus», ZPE 110, pp. 115-117.

Higbie, C. (2007): «Hellenistic Mythographers», en Woodard, R. D. (ed.), The Cambridge Companion to Greek Mythology, Cambridge, pp. 237-254.

Kenens, U. (2012): «Greek Mythography at Work: the Story of Perseus from Pherekydes to Tzetzes», GRBS 52, pp. 147-166.

Luppe, W. (1984): «Zum Tennes-Mythos im Mythographus Homericus, P. Hamb. 119», ZPE 56, pp. 31-32.

Luppe, W. (1993): «Helenos' und Kassandras 'Berufung'», APF 39, pp. 9-11.

Luppe, W. (1996a): «Die Ikarios-Sage im Mythographus Homericus», ZPE 112, pp. 29-33.

Luppe, W. (1996b): «Ein neues Fragment des Mythographus Homericus zu $\Psi$ 91-92», Prometheus 22(2), pp. 97-100.

Luppe, W. (1996c): «Mythographus Homericus P. Oxy. 4096 fr. 10», ZPE 112, pp. $25-28$.

Luppe, W. (1996d): «Neileus’ à $\pi$ oıkí nach Milet: Mythographus Homericus P. Oxy. 4096 fr. 3», Eikasmos 7, pp. 207-210.

Luppe, W. (1996-1997): «Ein Zeugnis für die Niobe-Sage in P. Oxy. 4096», WJA 21, pp. 153-159. 
Luppe, W. (1997a): «Die Psamathe- und die Plejaden-Sage im Mythographus Homericus P. Oxy. LXI 4096 fr. 1 und fr. 2 kol. II», APF 43 (1), pp. 1-6.

Luppe, W. (1997b): «Nachlese und Überlegungen zum Mythographus-HomericusCodex P.S.I. 1173», ZPE 116, pp. 13-18.

Luppe, W. (2009): «Zum Neuen Mythographus-Homericus-Papyrus (PSI XV 1505)», Prometheus 35 (3), pp. 219-220.

MacPhail, J. A. (ed.) (2011): Porphyry's Homeric Questions on the Iliad: Text, Translation, Commentary, Berlín-Nueva York.

Merkelbach, R. (1956): «Literarische Texte unter Ausschlu $\beta$ der christlichen: P. Schubart 21», APF 16, pp. 117-119.

Montanari, F. (1979): Studi di filologia omerica antica I, Pisa.

Montanari, F. (1988): «Filologia omerica antica nei papiri», en Mandilaras, V. G. y Adam, S. (eds.), Proceedings of the XVIII Congress of Papyrology, Athens 1986 II Atenas, pp. 337-344.

Montanari, F. (1995a): «The Mythographus Homericus», en Abbenes J. G. J., Slings S. R. y Sluiter I. (eds.), Greek Literary Theory after Aristotle: a Collection of Papers in Honour of D. M. Schenkeveld, Ámsterdam, pp. 135-172.

Montanari, F. (1995b): Studi di filologia omerica antica II, Biblioteca di Studi Antichi 19, Pisa, pp. 74-77.

Montanari, F. (2002): «Ancora sul Mythographus Homericus (e l'Odissea)», en Hourst, A. y Létoublon, F. (eds.), La Mythologie et l'Odyssée, Ginebra, pp. 129-144.

Nicole, J. (1891): Les Scolies Genevoises de l'Iliade, vols. I-II, Ginebra-Basilea, (reimp. Hildesheim, 1966).

Nünlist, R. (2009): The Ancient Critic at Work. Terms and Concepts of Literary Criticism in Greek Scholia, Cambridge.

Pagès, J. (2005): «Análisis del escolio D a Ilíada I 5: una aproximación a la génesis del corpus», en González Castro, J. F. et al., Actas del XI Congreso Español de Estudios Clásicos (Santiago de Compostela 15-20 de septiembre de 2003), Madrid.

Pagès, J. (2007): Mythographus Homericus: estudi i edició comentada, Tesis Doctoral, Barcelona.

Pagès, J. (2017): «Apollodorus' Bibliotheca and the Mythographus Homericus», en Pàmias, J. (ed.), Apollodoriana, Ancient Myths, New Crossroads. Studies in Honour of Francesc J. Cuartero, Berlín-Boston, pp. 66-81.

Pagès, J. (en preparación): «Aetia and Foundation Myth in the MH: some Examples from the Papyri», en Pagès, J. y Villagra, N. (eds.) (en preparación): Myths on the Margins of Homer, Berlín-Boston.

Pagès, J. y Villagra, N. (eds.) (en preparación): Myths on the Margins of Homer, Berlín-Boston.

Panzer, J. (1892): De Mythographo Homerico restituendo, Tesis Doctoral, Greifswald. 
Pfeiffer, R. (1937): «Hesiodisches und Homerisches: zu neuen und alten Papyri», Philologus 92, pp. 1-18.

Pontani, F. (2005): Sguardi su Ulisse: la tradizione esegetica greca all'Odissea, Roma.

Pontani, F. (en preparación): «Notes on the Manuscript Transmission of some Fragments of the Mythographus Homericus on the Odyssey», en Pagès, J. y Villagra, N., Myths on the Margins of Homer, Berlín-Boston.

Schironi, F. (2012): «Greek Commentaries», Dead Sea Discoveries 19, pp. 399-441.

Schironi, F. (2018): The Best of the Grammarians: Aristarchus of Samothrace and the Iliad. Ann Arbor.

Schmidt, M. (ed.) (1854): Didymi Chalcenteri Grammatici Alexandrini fragmenta, Leipzig.

Seaton, R. C. (1887): «The Symplegades and the Planctae», AJPh 8, pp. 433-440.

Sinatra, D. (2003): «Il Nostos di Argo. Gli itinerari della leggenda nella tradizione

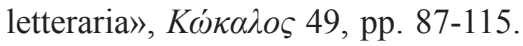

Tsagalis, C. (2011): «Towards an Oral, Intertextual Neoanalysis», Trends in Classics 3 (2), pp. 209-244.

Van der Valk, M. (1964): Researches on the Text and Scholia of the Iliad vol. II, Leiden.

Van Rossum-Steenbeek, M. (1996): «More on P. Oxy. LXI 4096, Mythographus Homericus», ZPE 113, pp. 24-26.

Van Rossum-Steenbeek, M. (1998): Greek Reader's Digests? Studies on a Selection of Subliterary Papyri, Leiden-Nueva York-Colonia.

Van Thiel, H. (2014): Scholia D in Iliadem. Proecdosis aucta et correctior 2014. Secundum codices manuscriptos, Colonia.

Vieille, C. (1998): «Les correspondances de prologues divins de la Guerre de Troie et du Mahabharata», en Isebaert, L. y Lebrun, R. (eds.), Quaestiones Homericae, Societé des Études Classiques, Lovaina-Namur, pp. 275-290.

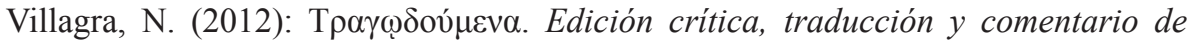
los fragmentos atribuidos a Asclepíades de Tragilo, Tesis Doctoral, Barcelona.

Villagra, N. (en preparación): «Towards an Edition and Commentary of the Mythographus Homericus to the Odyssey», en Pagès, J. y Villagra, N. (eds.), Myths on the Margins of Homer, Berlín-Boston.

Wilson, N. (2007): «Scholiasts and Commentators», GRBS 47, pp. 39-70.

Fecha de recepción de la primera versión del artículo: 28/04/2020

Fecha de aceptación: 16/05/2020

Fecha de recepción de la versión definitiva: 17/07/2020 